EarthArXiv coversheet for:

\title{
A calibration workflow for coastal dune models
}

Evan B. Goldstein ${ }^{*}$ and Laura J. Moore ${ }^{1}$

1 Department of Geological Sciences, University of North Carolina at Chapel Hill, 104 South Road, Mitchell Hall, Chapel Hill, NC 27599 USA

${ }^{*}$ Corresponding author: evan.goldstein@unc.edu (email) @ebgoldstein (Twitter)

This article is a postprint from Shore \& Beach, published by ASBPA. Shore \& Beach authors retain copyright over their work, and the journal also permits the distribution of typeset manuscripts (this was confirmed with the editor).

Shore \& Beach does not mint DOIs, therefore citation of this article should us the EarthArXiv $\mathrm{DOI}$ appended to the following citation:

Goldstein EB and Moore LJ (2018), A calibration workflow for coastal dune models, Shore \& Beach, Vol. 86, No. 3, p47-51<EarthArXiv DOl> 


\title{
A calibration workflow for coastal dune models
}

\author{
By \\ Evan B. Goldstein ${ }^{1^{\star}}$ and Laura J. Moore ${ }^{1}$ \\ 1) Department of Geological Sciences, University of North Carolina at Chapel Hill, \\ 104 South Road, Mitchell Hall, Chapel Hill, NC 27599 USA \\ "Corresponding author: evan.goldstein@unc.edu (email); @ebgoldstein (Twitter)
}

\begin{abstract}
Numerical models of coastal dune growth encode feedbacks and nonlinearities between sediment transport and plant growth. The range of processes and tunable parameters involved make model calibration an important step when using models for prediction. In this paper we outline a method to calibrate models of coastal dune formation and describe the process from end to end. The first step is collection of both topographic and vegetation data at two time periods with photogrammetry using the technique of structure-from-motion. Using the first topographic and vegetation capture as the model initial condition, the free parameters in the model are then tuned by running the model many times and adjusting the free parameters with a genetic algorithm, a machine learning technique. A set of parameters is found that produces the lowest prediction error - and in this way the model is calibrated for local conditions. We outline this routine, provide an example, and direct the reader to the open source software developed as part of the workflow presented here, which can be used with other dune models and/or other datasets.
\end{abstract}

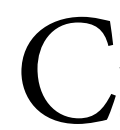
oastal foredunes provide protection from elevated water levels during storm and high water events (e.g. Sallenger 2000). Because dunes provide this protective service, storm forecasting and tools use dune parameters (i.e. height, volume) to predict storm impact (e.g. Stockdon et al. 2007). However, these tools often rely on dune topography that is not up to date because acquiring high-resolution topographic data before every potential storm is impractical and/or infeasible (e.g. cost and logistical difficulties). As a result, dune growth between storms is often unaccounted for in storm impact forecasts, limiting the accuracy of storm impact predictions.

Given that synoptic measurements of dune topography are made only periodically, an alternative approach to predicting dune height at any given time is to use quantitative, locally-parameterized and tested models to simulate foredune growth and recovery. There are several examples of spatially explicit dune models, such as Van Dijk et al. (1999), Durán and Moore (2013) and Keijsers et al. (2016). Previous work on modeling dune growth has focused on 2D shore-perpendicular models (Duran and Moore 2013; van Dijk et al. 1999) or 3D models with solely shore-perpendicular winds (Keijsers et al. 2016; Goldstein et al. 2017a). The require- ment of shore-perpendicular winds is a current limitation of coastal dune models generally.

All of these models have free parameters, especially embedded within formulations for sediment transport (e.g. proportionality constants) and vegetation growth (e.g. vertical growth rate, lateral growth rate). Parameter values may be set based on observations or heuristics. Here we describe an alternative approach for setting parameter values, in which observations are used along with a machine learning based procedure to automatically determine the appropriate parameter values.

\section{CALIBRATION WORKFLOW}

There are three components in the calibration workflow - spatially extensive topographic and vegetation data, Genetic Algorithm routine, and a coastal dune model. We now discuss each component.

\section{Topography and vegetation - structure-from-motion photogrammetry}

Our focus here is on the evolution of spatially explicit topography and vegetation fields of coastal dunes. Given that coastal dunes grow from feedbacks between vegetation and sediment transport, both a topographic surface and a vegetation field are needed for the
ADDITIONAL KEYWORDS: Genetic algorithms, machine learning, coastal dunes, coastal dune modeling, model tuning

Manuscript submitted 19 March 2018, revised and accepted: 28 June 2018.

pre- and post- data. Lidar provides a means for collecting spatially explicit, high-resolution topographic measurements, but extracting dune vegetation characteristics from Lidar is nontrivial (e.g. Yousefi Lalimi et al. 2017). Furthermore, it is often the case that Lidar data collection is opportunistic, most often focused on the time period immediately before and after a storm event. Rarely are Lidar captures timed to explicitly capture and quantify dune growth. Furthermore, there may be long time intervals between captures. Even where lidar has been captured frequently, the intervals between acquisitions are longer than a year - for example the Cape Lookout region of North Carolina has 12 available datasets spanning 1997 to 2016. Though Lidar can be used for calibration, we outline a technique here using data from the structure-from-motion technique, which can be obtained quickly and easily with inexpensive, off-the-shelf technology, allowing collection of topographic data as frequently as desired.

Structure-from-Motion Multi-viewStereo (SfM) photogrammetry is a technique whereby many photos of a surface, captured from varying perspectives, are used to generate an orthophotomosaic (a composite of images that preserves spatial scales) and a digital surface model (e.g. James and Robson 2012, Westoby et al. 2012; Fonstad et al. 2013; Bryson et al. 2013, Mancini et al. 2013; Scarelli et al. 2016; Scarelli et al. 2017). Recent work indicates that a kite-based camera is able to provide images that are ideally suited to the SfM process over coastal dunes (Goldstein et al. 2015; Duffy and Anderson 2016; Conlin et al. 2018). A 


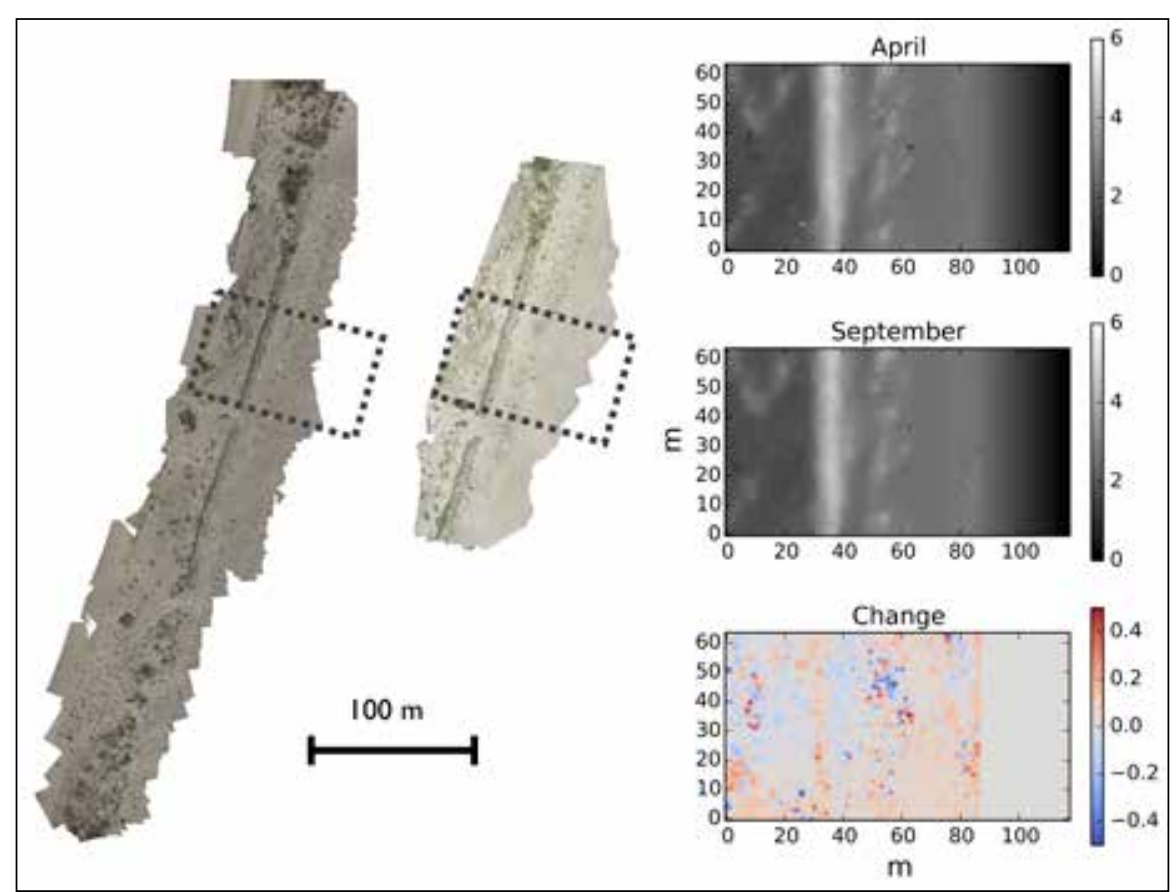

Figure 1. Left: Example of structure-from-motion derived orthophotomosaics from Fort Fisher, NC, at two time periods. Right: Extracted digital surface models of the dashed grid area that are rotated and resamples to be a $1 \mathrm{~m} x$ $1 \mathrm{~m}$ resolution. Lower panel shows the landscape change between captures.

Figure 2. Schematic of a genetic algorithm. An initial population of three individuals (yellow, blue, and pink) is evaluated at time TO. Each individual consists of four tunable parameters. After the first iteration, the best solution persists. A good solution undergoes "crossover" with the best solution. The worst solution is removed and replaced by a "mutated" version of the "crossover" (mutations in green).

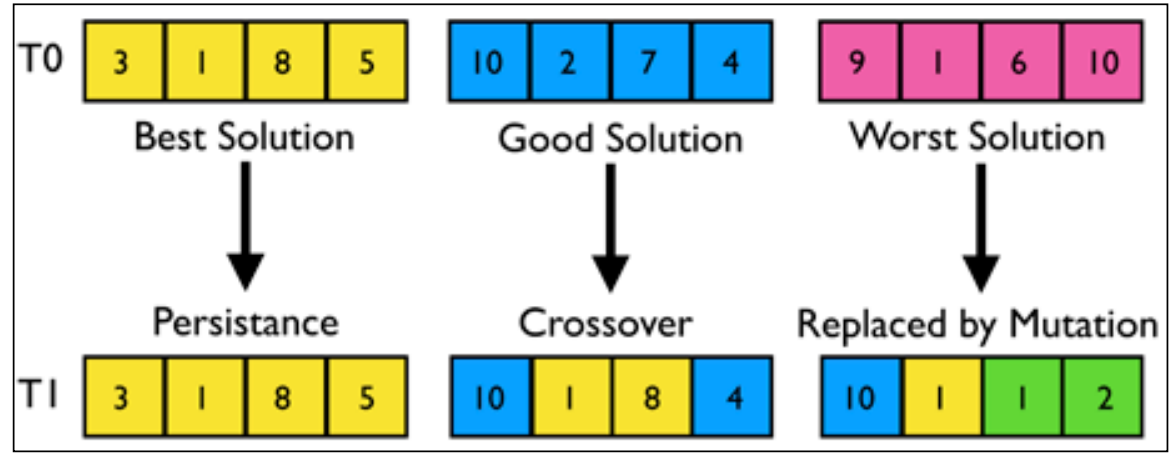

GPS/Global Navigation Satellite System (GNSS) survey conducted concurrently with the SfM flight provides ground control points (sites of known XYZ position). At least two flights are needed for the workflow discussed here. The first capture is used as an initial condition for the model. The second capture is used to compare with model results.

We obtain the key data product used in the study from the aerial survey and SfM photgrammetry - a dense point cloud. Using images matched in the multi-view stereo algorithm from SfM, a dense point cloud is constructed using all the photographs. Flying a kite based setup point cloud so that the $1 \mathrm{~m} \times 1 \mathrm{~m}$ model grid is aligned with the local shoreline (i.e. model gridlines are shore-normal and shore-parallel).

Dense point clouds also record color information (red, green, and blue color bands in this case). We can use this information to construct a red-greenblue (RGB) grid with the same $1 \mathrm{~m} \mathrm{x}$ $1 \mathrm{~m}$ resolution. We use this $\mathrm{RGB}$ grid to develop an initial vegetation surface. This calibration and classification of vegetation percent cover can also be done via ground-truthing with quadrats, using small-scale grids or through the use of other automated image classification techniques (e.g. Nolet et al. 2017; Duffy et al. 2018). In this example we have used the grayscale value of each pixel and developed a bespoke calibration curve for each capture (i.e. relating grayscale to vegetation percent cover). Prior to building the $1 \mathrm{~m} x 1 \mathrm{~m}$ vegetation grid, we again rotate the point cloud so that the $1 \mathrm{~m} \times 1 \mathrm{~m}$ grid is aligned with the shoreline.

\section{Genetic algorithm}

From the SfM photogrammetry, we can obtain digital surface models and a spatial model of the vegetation field. Our goal in calibrating the model with these data is to provide the initial conditions (topography and vegetation) for the model, run the model, and then compare the results to a known final condition (the second SfM capture). Model results and the known final condition can be compared using a specific quantitative error metric - i.e. mean squared error, Brier skill score, etc. (Sutherland et al. 2004).

A given combination of specific values for each parameter produces a specific model outcome and a specific error value when compared to the known final condition. Therefore, any set of model parameters values are directly related to a specific error value (given the caveat that the dune models are deterministic). Using this relationship, we can look for specific parameter values that give the lowest error by searching. But how do we search through all the possible combinations of free parameters? Brute force techniques work when there are only a few free parameters, but coastal dune models have multiple free parameters. To do this we take a machine learning approach and use genetic algorithms (GA; Holland 1975; Mitchell 1995; 1998), which have been used to tune other morphodynamic mod- 


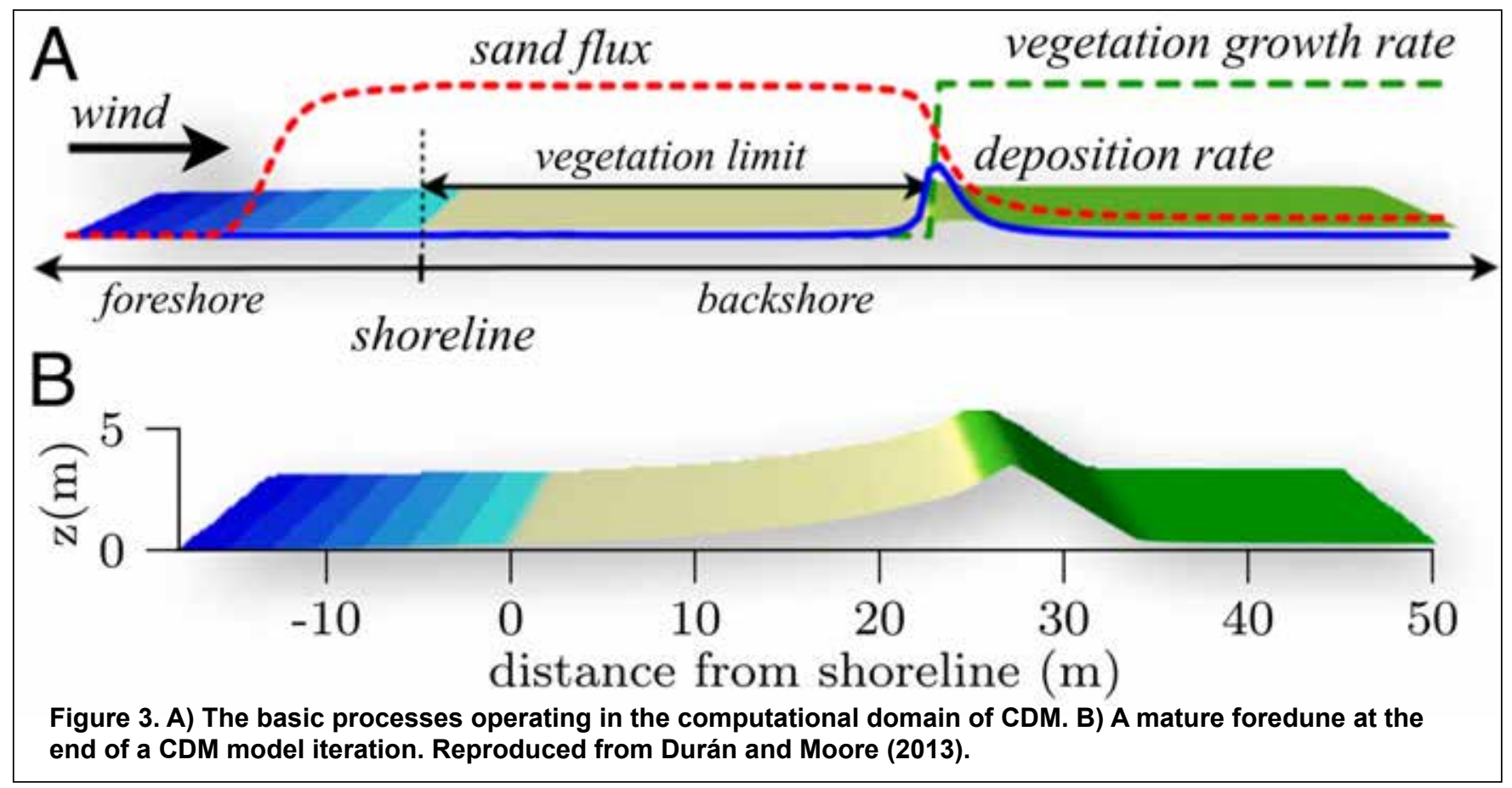

els (Knaapen and Hulscher 2002; 2003; Ruessink 2005; Komurcu et al. 2008).

Genetic algorithms are populationbased machine learning techniques that operate on rules based on natural selection (Figure 2). Imagine there are four free parameters embedded within the formulations of vegetation growth and aeolian sediment transport. We describe each combination of unique values of the four parameters as an "individual." Now consider a population of such individuals (i.e. a population of sets of parameter values) - we now run the model for each individual, and each individual is now associated with an error. With this population of individuals, we apply "evolutionary" rules - given an initial population, the "individuals" with the smallest error are kept; the individuals with the most error are discarded. After each "generation," individuals are created by "reproduction" (combining two individuals; mixing and matching the parameters) and mutation (randomly adjusting the parameters of a given individual. Eventually, after many generations of keeping, discarding, reproducing, and mutating, we are left with a set of individuals that are defined by parameters that give a low error, a solution that we hope is at or near the global minima in error possible for the given model. The low error solution can be considered the calibrated version of the model.

Model performance in this paper is calculated by comparing model results to observations of topography using mean squared error, a point-based skill score (Sutherland et al. 2004). Displacement based skill scores (e.g. Bosboom and Reniers 2014) are also present in the code.

\section{A COASTAL DUNE MODEL}

We coupled the genetic algorithm routine described above to a coastal dune model. Any coastal dune model could be used, but here we use the Coastal Dune Model (CDM) of Durán and Moore (2013) (Figure 3), a spatially explicit model developed based on previous models of desert dunes (e.g. Schwämmle and Hermann 2003; Durán and Herrmann 2006; Durán et al. 2010). We summarize the basic aspects of the model here. Using the initial topographic and vegetation field, a wind routine is used to calculate the shear stress applied to the surface (Weng et al. 1991). This shear stress field is modified by the presence of vegetation (which reduces shear stress) and flow separation in the lee of dunes, and is then used to calculate aeolian sand flux at all points on the model grid. Spatial gradients in sand flux drive changes in topography, subject to constraints on the angle of repose for dry sand. Finally vegetation changes are then calculated for each grid cell of the model - the growth of vegetation percent cover in each model cell as a function of sand accretion/erosion and lateral propagation from nearby cells. We point the interested reader to the works of Durán and Moore (2013), Moore et al. (2016a) and Goldstein et al. (2017a) for information on the model and basic dynamics, the cross-shore dynamics, and the alongshore dynamics (respectively).

\section{EXAMPLE}

We describe step-by-step, this calibration routine using the CDM, a genetic algorithm routine, and a published example data set from Fort Fisher State Recreation Area, NC (Goldstein and Ells 2017; Goldstein et al. 2017b; Ells and Pickett 2017). After performing the processing, rotating and resampling routines, we have the grids to use as initial data and final (testing) data for the calibration routine. We initialize the genetic algorithm routine with a population of 10 individuals and run the model for 20 generations. There are several tunable parameters in the CDM model, including two sensitivity terms that control the growth of vegetation - a term that controls the sensitivity of plant growth to burial, and a term to account for the sensitivity of lateral propagation to burial. In addition, there are parameters that control the reduction of shear stress applied to the sand surface as a function of vegetation, and there are aeolian transport coefficients. An example of model tuning with four tunable parameters is shown in Figure 4. Within several generations of the genetic algorithm the routine converges on the parameters that yield the lowest error.

\section{FUTURE WORK}

Beyond its utility in calibrating coastal dune models, the calibration workflow we describe is flexible, and can be used 


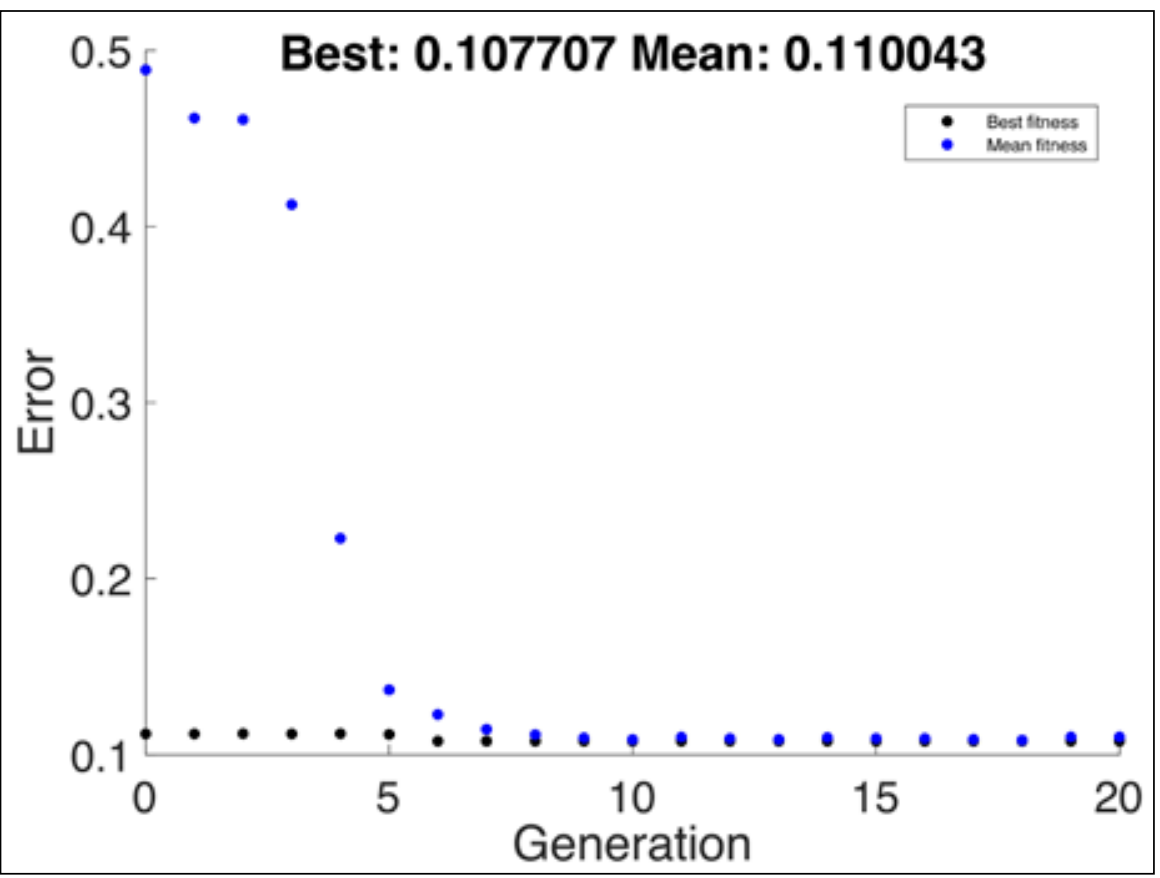

Figure 4. An example from tuning the CDM with a genetic algorithm. Using a population of 10 and $\mathbf{2 0}$ generations, the routine fully converges on the best parameter values (lowest error) by the 7th generation.

with other morphodynamic models. This includes more complex coastal models such as Windsurf - a spatially explicit model of vegetated coastal dune growth (CDM; Durán and Moore 2013) coupled to a coastal hydrodynamic model (XBeach; Roelvink et al. 2009). Preliminary work using Windsurf has shown skill in projecting fair-weather recovery of beaches and dunes over monthly to annual timescales and in multiple coastal settings (Moore et al. 2016b; Cohn et al. 2016). We expect that models with many free parameters will benefit most from tuning using a genetic algorithm (vs. a brute force approach) such as the one we presented here. We hope to work toward the development of several examples of image pairs to be used as open data for dune model calibration. In addition to the data described above, the code used here is also available online: the current version of CDM is available here

\section{REFERENCES}

Bosboom, J., and A.J.H.M. Reniers, 2014. "Displacement-based error metrics for morphodynamic models" Advances in Geosciences, 39, 37.

Bryson, M., M. Johnson-Roberson, R.J. Murphy, and D. Bongiorno, 2013. "Kite aerial photography for low-cost, ultra-high spatial resolution multi-spectral mapping of intertidal landscapes." PloS one, 8(9), e73550.

Cohn, N, B. Hoonhout, P. Ruggiero, L.J. Moore, S. de Vries, J.A. Roelvink, O. Durán Vinent, and E.B. Goldstein, 2016. "Exploring nearshore beach-dune interaction through a coupled modeling framework." American Geophysical Union Ocean Science Meeting, 21-26 February 2016; New Orleans, LA, USA

Conlin, M., N .Cohn, and P. Ruggiero, 2018. "A quantitative comparison of low-cost Structure from Motion (SfM) data collection platforms on beaches and dunes." J. Coastal Research.

Duffy, J.P., and K. Anderson, 2016. "A 21st-century renaissance of kites as platforms for proximal sensing." Progress in Physical Geography, 40(2), 352-361.

Duffy, J.P., L. Pratt, K. Anderson, P.E. Land, and J. D. Shutler, 2018. "Spatial assessment of intertidal seagrass meadows using optical imaging systems and a lightweight drone." Estuarine, Coastal and Shelf Science, 200, 169-180.

Durán, O., and L. J. Moore, 2013. "Vegetation controls on the maximum size of coastal dunes. Proceedings of the National Academy of Sciences, 110(43), 17217-17222.

Durán, O., and H. J. Herrmann, 2006. Vegetation against dune mobility." Physical review letters, 97(18), 188001.

Durán, O., E.J. Parteli, and H.J. Herrmann, 2010 "A continuous model for sand dunes: Review, new developments and application to barchan dunes and barchan dune fields." Earth Surface Processes and Landforms, 35(13), 1591-1600.

Ells, K., and A. Picket, 2017. "Kite-based Structurefrom-Motion survey of Fort Fisher State Recreation Area beach, North Carolina, USA, 11/4/2016 (Version 1)." figshare. https://doi. org/10.6084/m9.figshare.4746613.v1. 
Fonstad, M.A., J.T. Dietrich, B.C. Courville, J.L. Jensen, and P. E. Carbonneau, 2013. “Topographic structure from motion: a new development in photogrammetric measurement." Earth Surface Processes and Landforms, 38(4), 421-430.

Goldstein, E.B., L.J. Moore, and O. Durán Vinent, 2017a. "Lateral vegetation growth rates exert control on coastal foredune hummockiness and coalescing time." Earth Surface Dynamics, 5(3), 417

Goldstein, E., K. Ells, and E. deVries Mullins, 2017b. "Kite-based Structure-from-Motion survey of Fort Fisher State Recreation Area beach, North Carolina, USA, 9/12/2016 (Version 2)." figshare. https://doi.org/10.6084/ m9.figshare.3856248.v2.

Goldstein, E., and K. Ells, 2017. "Kite-based Structure-from-Motion survey of Fort Fisher State Recreation Area beach, North Carolina, USA, 4/26/2016 (Version 2)." figshare. https://doi. org $/ 10.6084 / \mathrm{m} 9$. figshare.3370648.v2.

Goldstein E.B., A.R. Oliver, E. DeVries, L.J. Moore, and T. Jass, 2015. "Ground control point requirements for structure-from-motion derived topography in low-slope coastal environments." PeerJ PrePrints3:e1444v1 https:// doi.org/10.7287/peerj.preprints.1444v1.

Holland, J.H., 1975. "Adaptation in natural and artificial systems. An introductory analysis with application to biology, control, and artificial intelligence." Ann Arbor, MI: University of Michigan Press.

James, M.R., and S. Robson, 2012. "Straightforward reconstruction of 3D surfaces and topography with a camera: Accuracy and geoscience application." J. Geophysical Research: Earth Surface, 117(F3).

Keijsers, J.G.S., A.V. De Groot, and M.J.P.M. Riksen, 2016. "Modeling the biogeomorphic evolution of coastal dunes in response to climate change." J. Geophysical Research: Earth Surface, 121(6), 1161-1181.

Knaapen, M.A.F., and S.J. Hulscher, 2002. "Regeneration of sand waves after dredging." Coastal Engineering, 46(4), 277-289.
Knaapen, M.A.F., and S. J. Hulscher, 2003. "Use of a genetic algorithm to improve predictions of alternate bar dynamics." Water Resources Research, 39(9).

Komurcu, M.I., N. Tutkun, I.H. Ozolcer, and A. Akpinar, 2008. "Estimation of the beach bar parameters using the genetic algorithms." Applied Mathematics and Computation, 195, 49-60.

Mancini, F.; M. Dubbini, M. Gattelli, F. Stecchi, S. Fabbri, and G. Gabbianelli, 2013. "Using unmanned aerial vehicles (UAV) for highresolution reconstruction of topography: The structure from motion approach on coastal environments." Remote Sensing, 5(12), 6880-6898.

Mitchell, M., 1995. "Genetic algorithms: An overview." Complexity, 1(1), 31-39.

Mitchell, M., 1998. An Introduction to Genetic Algorithms. MIT Press.

Moore, L. J., O.D. Vinent, and P. Ruggiero, 2016a. "Vegetation control allows autocyclic formation of multiple dunes on prograding coasts." Geology, 44(7), 559-562.

Moore, L.J., J.A. Roelvink, P. Ruggiero, N. Cohn, B. Hoonhout, O. Durán Vinent, E.B. Goldstein, and S. de Vries, 2016b. "Crossing the Shoreline Divide: Toward modeling the co-evolution of dune, beach and nearshore systems." American Geophysical Union Ocean Science Meeting, 21-26 February 2016; New Orleans, LA, USA

Nolet, C., M. van Puijenbroek, J. Suomalainen, J. Limpens, and M. Riksen, 2017. "UAV-imaging to model growth response of marram grass to sand burial: Implications for coastal dune development." Aeolian Research.

Roelvink, D., A. Reniers, A.P. Van Dongeren, J.V.T de Vries, R. McCall, and J. Lescinski, 2009. "Modelling storm impacts on beaches, dunes and barrier islands." Coastal Engineering, 56(11-12), 1133-1152.

Ruessink, B.G., 2005. "Calibration of nearshore process models: Application of a hybrid genetic algorithm." J. Hydroinformatics, 7, 135-149.

Sallenger Jr., A.H. (2000). "Storm impact scale for barrier islands." J. Coastal Res., 890-895.

Scarelli, F.M., L. Cantelli, E.G. Barboza, M.L.C.C.

Rosa, and G. Gabbianelli, 2016. "Natural and Anthropogenic Coastal System Comparison Using DSM from a Low Cost UAV Survey (Capão Novo, RS/Brazil)." J. Coastal Res., 75, 1232-1236.

Scarelli, F.M., F. Sisitilli, S. Fabbri, L. Cantelli, and E.G. Barboza, 2017. "Seasonal dune and beach monitoring using photogrammetry from UAV surveys to apply in the ICZM on the Ravenna coast (Emilia-Romagna, Italy)." Remote Sensing Applications: Society and Environment, 7, 27-39.

Schwämmle, V., and H.J. Herrmann, 2003. "Geomorphology: Solitary wave behaviour of sand dunes." Nature 426:619-620.

Stockdon, H.F., A.H. Sallenger Jr., R.A. Holman, and P.A. Howd, 2007. "A simple model for the spatially-variable coastal response to hurricanes." Marine Geology, 238(1-4), 1-20.

Sutherland, J., A.H. Peet, and R. Soulsby, 2004 "Evaluating the performance of morphological models." Coastal Engineering, 51(8-9), 917-939.

Van Dijk, P.M., S.M. Arens, and J. H. Van Boxel, 1999. "Aeolian processes across transverse dunes. II: Modelling the sediment transport and profile development." Earth Surface Processes and Landforms, 24 (4), 319-333.

Westoby, M.J., J. Brasington, N.F. Glasser, M.J. Hambrey, and J.M. Reynolds, 2012. "Structurefrom-Motion' photogrammetry: A low-cost, effective tool for geoscience applications." Geomorphology, 179, 300-314.

Weng, W.S., J.C.R. Hunt, D.J. Carruthers, A. Warren, G.F.S. Wiggs, I. Livingstone, and I. Castro, 1991. "Air flow and sand transport over sand dunes." Acta Mech., Suppl. 2, 1-22.

Yousefi Lalimi, F., S. Silvestri, L.J. Moore, and M. Marani, 2017. "Coupled topographic and vegetation patterns in coastal dunes: Remote sensing observations and ecomorphodynamic implications." J. Geophysical Research: Biogeosciences, 122(1), 119-130. 